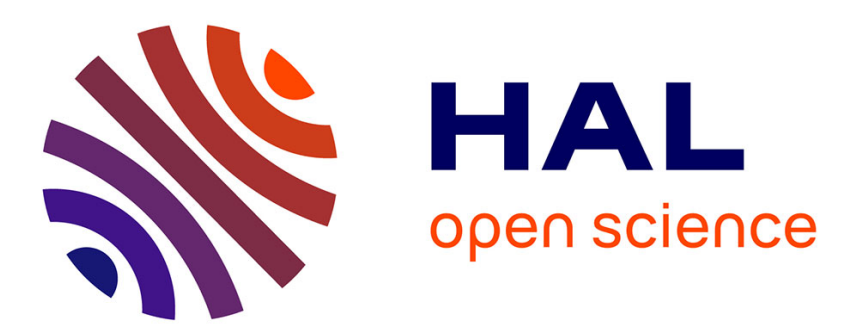

\title{
Silicon Nitride and YMgSiAlON Glass Study by Mechanical Spectroscopy
}

B. Doen, P. Gadaud

\section{To cite this version:}

B. Doen, P. Gadaud. Silicon Nitride and YMgSiAlON Glass Study by Mechanical Spectroscopy. Journal de Physique IV Proceedings, 1996, 06 (C8), pp.C8-707-C8-710. 10.1051/jp4:19968154 jpa00254588

\section{HAL Id: jpa-00254588 https://hal.science/jpa-00254588}

Submitted on 1 Jan 1996

HAL is a multi-disciplinary open access archive for the deposit and dissemination of scientific research documents, whether they are published or not. The documents may come from teaching and research institutions in France or abroad, or from public or private research centers.
L'archive ouverte pluridisciplinaire HAL, est destinée au dépôt et à la diffusion de documents scientifiques de niveau recherche, publiés ou non, émanant des établissements d'enseignement et de recherche français ou étrangers, des laboratoires publics ou privés. 


\title{
Silicon Nitride and YMgSiAlON Glass Study by Mechanical Spectroscopy
}

\author{
B. Doen and P. Gadaud
}

LMPM, ENSMA Téléport 2, BP. 109, 89960 Futuroscope cedex, France

\begin{abstract}
Si}_{3} \mathrm{~N}_{4} / \mathrm{TiN}$ and $\mathrm{YMgSiAlON} / \mathrm{SiC}$ composites have been studied by isothermal mechanical spectroscopy over a large frequency range. Internal friction curves obtained for the composite $\mathrm{Si}_{3} \mathrm{~N}_{4}-\mathrm{TiN}(30 \% \mathrm{vol})-\mathrm{Al}_{2} \mathrm{O}_{3}, \mathrm{Y}_{2} \mathrm{O}_{3}(7.5 \% \mathrm{vol})$ exhibit a thermally activated pseudo peak superposed on a non purely exponential background. We can assume that this maximum is due to relaxations in the compressed intergranular glassy films. The apparent dynamical parameters deduced from its shift $\left(11.2 \mathrm{eV}\right.$ and $\left.3 \cdot 10^{-45} \mathrm{~s}\right)$ are unusual as observed in amorphous materials. YMgSiAlON glass has a composition very similar to the one of the intergranular phase of $\mathrm{Si}_{3} \mathrm{~N}_{4} / \mathrm{TiN}$ composite. The damping curves obtained for $\mathrm{YMgSiAlON} / \mathrm{SiC}$ composites above the glass transition temperature are pure exponential backgrounds. An original analysis of these curves allows to determine an activation energy of about $3.6 \mathrm{eV}$. This value is more realistic for an elementary diffusion mechanism in a glass near $\mathrm{Tg}$.
\end{abstract}

\section{INTRODUCTION}

Silicon nitride has excellent mechanical properties at high temperature. Although it suffers from brittleness (which makes its forming difficult), superplastic deformation can be performed at high temperature under low strain rate [1]. These deformations are controlled by the viscous flow of the glassy intergranular phase. We propose to characterize micromechanisms of relaxation in the intergranular phase above Tg by mechanical spectroscopy. The determination of activation energies and relaxation time will allow us to identify which type of mechanism is activated at high temperature under low strain in the composite. Studying both $\mathrm{Si}_{3} \mathrm{~N}_{4} / \mathrm{TiN}$ and $\mathrm{YMgSiAlON} / \mathrm{SiC}$ we will compare the influence of the structure (ceramic composite or glass composite) on the behavior of the YMgSiAlON glass.

\section{MATERIALS AND EXPERIMENTAL TECHNIQUES}

$\mathrm{Si}_{3} \mathrm{~N}_{4} / \mathrm{TiN}$ composite was supplied by EPFL Lausanne and comes from Ceramique Technique Desmarquet (France). Its commercial name is KERSIT 601. The composite was obtained by slip-casting and pressureless sintering of mixed $\mathrm{Si}_{3} \mathrm{~N}_{4}$ powder and TiN particles (30\% vol., average size : $\left.2 \mu \mathrm{m}\right)$ using $\mathrm{Y}_{2} \mathrm{O}_{3}$ and $\mathrm{Al}_{2} \mathrm{O}_{3}(7,5 \% \mathrm{wt})$ as sintering aids [2]. YMgSiAlON/SiC composite was supplied by the University of Rennes I. They were prepared from an amorphous YMgSiAlON powder mixed with SiC particles ( $40 \%$ vol.) whose mean grain size was $6 \mu \mathrm{m}$. That mixture was then hot pressed under neutral atmosphere [3].

To measure internal friction and shear modulus variations we used a low frequency forced torsional pendulum [4]. Tests were carried out at fixed temperature (between $800 \mathrm{~K}$ and $1200 \mathrm{~K}$ ) under high vacuum $\left(10^{-5} \mathrm{~Pa}\right)$ over a four decades frequency range (from $10^{-3} \mathrm{~Hz}$ to $10 \mathrm{~Hz}$ ). Measurements were performed for decreasing temperatures to ensure a constant microstructure during the tests.

Samples were annealed in the pendulum under high vacuum. The glass composite was heat treated $4 \mathrm{H}$ at $1213 \mathrm{~K}(\mathrm{R} 1213)$ then $6 \mathrm{H}$ at $1249 \mathrm{~K}(\mathrm{R} 1249)$ and $6 \mathrm{H}$ at $1275 \mathrm{~K}(\mathrm{R} 1275)$. 


\section{EXPERMENTAL RESULTS AND DISCUSSION}

\section{1. $\mathrm{Si}_{3} \mathrm{~N}_{4} / \mathrm{TiN}$}

Figure I shows the internal friction spectra obtained for the composite $\mathrm{Si}_{3} \mathrm{~N}_{4} / \mathrm{TiN}$ as a function of frequency for different temperature measurements. Damping spectra have a complex shape : superposition of a non purely exponential background at low frequencies and a pseudo peak at high frequencies separated by a transitory flat background. The position of the maximum of damping shifts by changing the temperature of the isothermal measurements.

A.Lakki and R.Schaller [5], for this TiN composite, and Gadaud et al. [6], for a TiC composite, found that this shift obeys to an Arrhenius law. They respectively deduced an activation energy of 11 and 10.4 $\mathrm{eV}$. Moreover, A.Lakki observed a disappearance of the mechanical loss maximum after successive heat treatments; others investigations showed an increase in cristallinity all along these heat treatments. Hence, this peak seems to be due to relaxation mechanisms in the amorphous intergranular phase. Comparisons with the damping spectra of the monolithic material show that TiN particles do not influence the presence of the peak, although it might affect its characteristics.

In this study, the relaxation parameters were established -figure2- using the Arrhenius temperature dependence of $F_{0}$ (frequency at the mechanical loss maximum). The activation energy and the time relaxation obtained were respectively: $\mathrm{Ea}=11.2 \mathrm{eV}$ and $\tau=3.10^{-45} \mathrm{~s}$. These values do not correspond to the relaxation of an elementary mechanism but rather to a correlated mechanism in the amorphous phase.

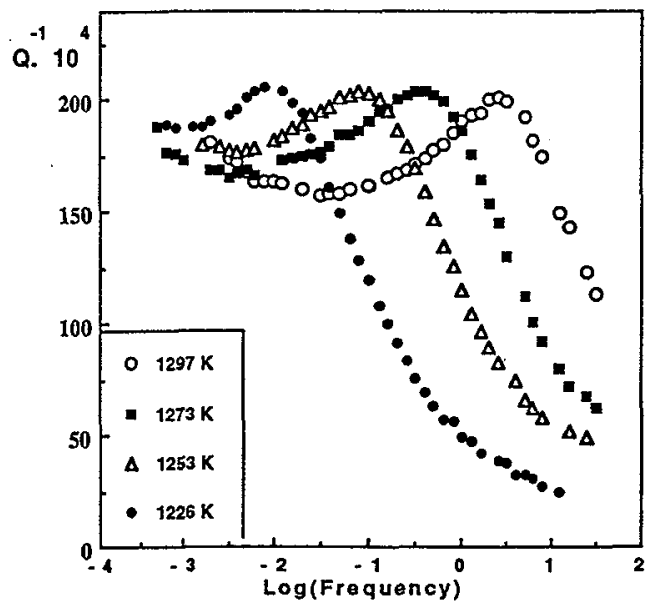

Figure 1: Internal friction spectra versus frequency in $\mathrm{Si}_{3} \mathrm{~N}_{4} / \mathrm{TiN}$ composite.

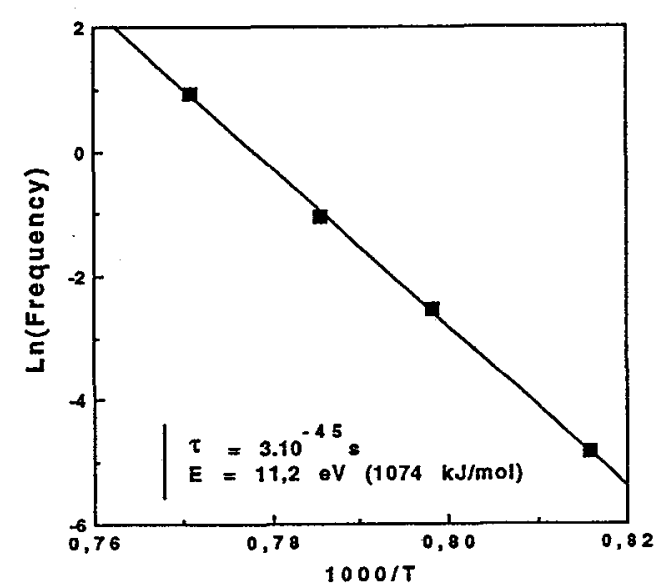

Figure 2: Arrhenius plot deduced from the apparent maximum positions.

\subsection{YMgSiAION/SiC}

Internal friction curves obtained for $\mathrm{YMgSiAlON} / \mathrm{SiC}$ as a function of frequency at a given temperature are pure exponential backgrounds. Figure 3 shows that mechanical loss increases with the temperature of measurement whereas shear modulus decreases with it (figure4); this kind of results has been previously observed in different glasses $[7,8]$ but not yet qualitatively analyzed.

Starting from the model developped by Schoeck to describe the rise in the internal friction at high temperature [9], the internal friction curve follows a law of the type : $\mathrm{Q}^{-1}=\mathrm{K} /[\omega \cdot \exp (\mathrm{Ea} / \mathrm{kT})]^{\mathrm{n}}$ (1) where $\mathrm{Q}^{-1}$ is the mechanical damping, Ea the activation energy of a thermally activated mechanism, $\mathrm{k}$ the Boltzmann's constant, $\mathrm{K}, \mathrm{n}$ are constants over a limited temperature range, $\omega$ the excitation pulsation, $\mathrm{T}$ the absolute temperature. This model has been applied for different materials : in the case of nickel aluminides Chakib et al. [10] found that $\mathrm{n}$ is quite constant over a large temperature range, furthermore, Gadaud et al. [11] showed that $\mathrm{n}$ can obey to a linear law of temperature in silicon. 


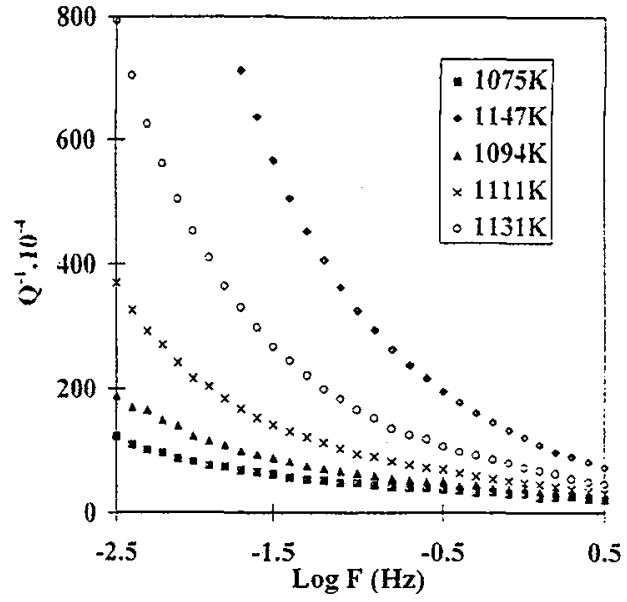

Figure 3: Internal friction backgrounds versus frequency in YMgSiAlON/SiC composite.

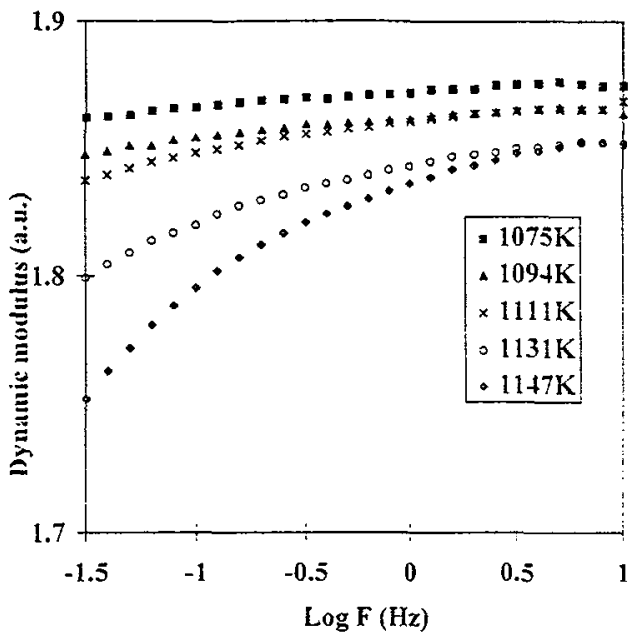

Figure 4: Relative evolution of shear modulus versus frequency in YMgSiAlON/SiC composite.

In any case we can assume that the background follows the law : $\mathrm{Q}^{-1}=\left[\mathrm{K}^{*} / \omega \cdot \exp (\mathrm{Ea} / \mathrm{kT})\right]^{\alpha(\mathrm{T})}$ (2) where $0<\alpha(T)<1$ and $K^{*}$ constant over the temperature range considered.

This equation leads to $: \ln \left(Q^{-1}\right)=-\alpha(T) \ln (\omega)+\alpha(T) \ln \left(K^{*}\right)-\alpha(T)$.Ea/(kT) (3). Plotting $\ln \left(Q^{-1}\right)$ as a function of $\ln (\omega)$ at a given temperature we obtain a straight line whose slope is $\alpha(\mathrm{T})$, see figure 5 , where $\alpha$ is determined for five different temperatures. Once $\alpha$ is determined, we can divide $\ln \left(\mathrm{Q}^{-1}\right)$ by it and equation (3) becomes : $\ln \left(\mathrm{Q}^{-1}\right) / \alpha(\mathrm{T})=-\ln (\omega)+\ln \left(\mathrm{K}^{*}\right)$-Ea/kT (4)

Plotting $\ln \left(\mathrm{Q}^{-1}\right) / \alpha(\mathrm{T})$ as a function of $1 / \mathrm{T}$ for a given frequency we can determine the activation energy of the thermally activated mecanism considered (figure 6). It's remarkable that the obtained activation energy remains equal to $3.6 \pm 0.1 \mathrm{eV}$ for each heat treatment.

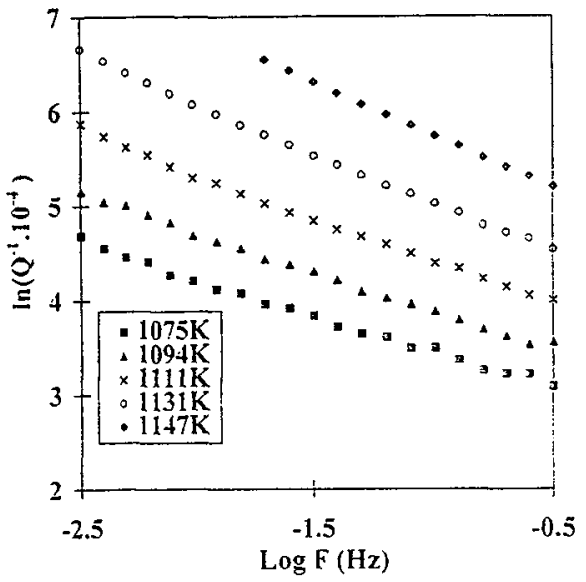

Figure 5: Logarithm of internal friction versus frequency in YMgSiAlON/SiC composite.

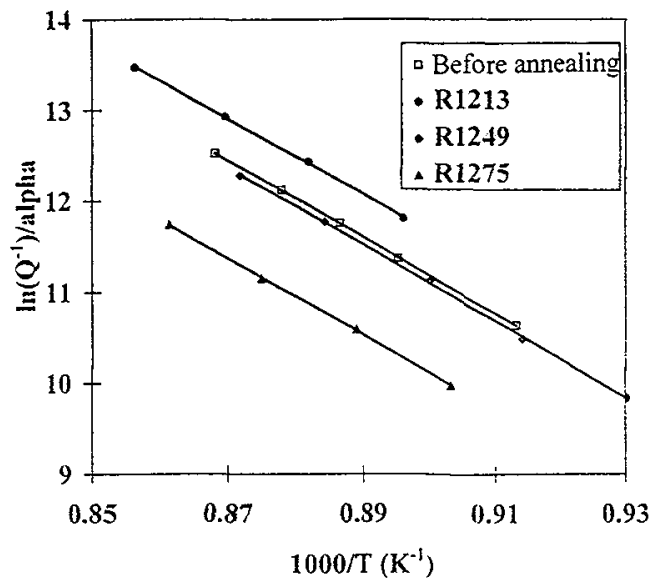

Figure 6: Deduced Arrhenius plots for different heat treatments in $\mathrm{YMgSiAlON} / \mathrm{SiC}$ composite.

Measurements performed after successive annealings show that internal friction decreases progressively (figure 7) and that shear modulus increases (figure 8), which certainly comes from the beginning of cristallyzation. 


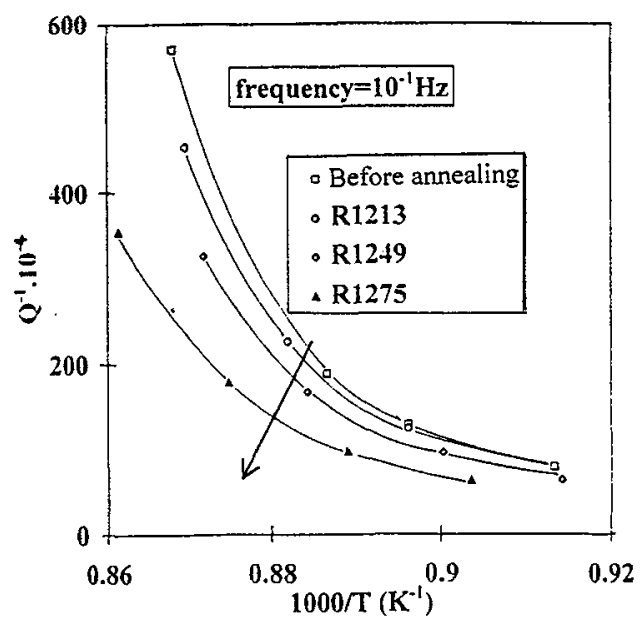

Figure 7: Internal friction versus 1000/T after annealings in YMgSiAlON/SiC composite.

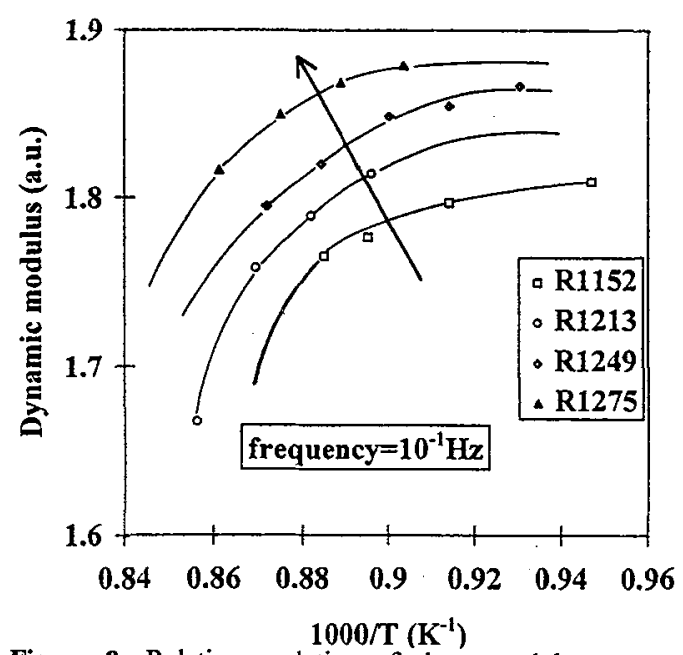

Figure 8: Relative evolution of shear modulus versus 1000/T after annealings in YMgSiAlON/SiC composite.

\section{CONCLUSION}

This work compares the viscoelastic behavior of YSiAlON glass as matrix in YMgSiAlON/SiC composite and as intergranular phase in $\mathrm{Si} 3 \mathrm{~N} 4 / \mathrm{TiN}$ composite. In the first case, an original analysis of the low frequency background associated to the decreasing viscosity, allows one to determine an activation energy proper to an elementary relaxation mechanism. To progress in its understanding chemical investigations have to be carried on.

On the other hand, a similar glass under compressed intergranular films form exhibits a pseudo peak which apparent activation energy is very different from the latter. It may correspond to correlated mechanisms due to internal stresses. However energy values deal with usual creep ones. To describe these correlations we have to compare the influence of the microstructural parameters.

\section{ACKNOWLEDGEMENTS}

This work was financially supported by the Region Poitou-Charente. YMgSiAlON/SiC composites were supplied by P.Verdier (University of Rennes I) thanks to T.Rouxel (ENSCI Limoges), and $\mathrm{Si}_{3} \mathrm{~N}_{4} / \mathrm{TiN}$ composites by A.Lakki and R.Schaller (EPFL Lausanne).

\section{References}

[1] Rouxel T. and Wakai F., Acta metall. mater., 41 (1993) 3203.

[2] Torre J.P. and Bigay Y., ceram Engng Sci., 7 (1986) 893.

[3] Gamier C., Thèse de l'Université of Rennes I (1993).

[4] Woirgard J., Mazot Ph. and Rivière A., J.Phys., 42, (oct. 1981) C5-1135.

[5] Lakki A. and Schaller R, Proceedings of the $13^{\text {th }}$ Ris $\phi$ International Symposium on Materials Science", Denmark 1992, ed. by S.I.Andersen et al., p.311.

[6] Gadaud P., Guisolan B., Kulik A. and Schaller R., Rev. Sci. Instrum. 10, 61 (1990) 2671.

[7] Etienne S., Cavaille J.Y. and Perez J., Colloque C9, supplement to number 12, 44 (1983) C9-157.

[8] Perez J., Colloque C10, supplement to number 12, 46 (1985) C10-427.

[9] Schoeck G., Acta Metall., 12 (1964) 1466.

[10] Chakib K., Thèse de l'Université de Poitiers (1993).

[11] Gadaud P., Woirgard J., Mazot P., Demenet J.L. and De Fouquet J., Colloque C8, supplement to number 12, 48 (1987) C8-101. 